\title{
قياس القروق لمفهوم الذات الأكاديمي لاى الطلبة حسب المستويات التعليمية لنظام (ل.م.د)
}

Measuring the differences in the students' academic self-concept according to the educational levels of the LMD system

تاريخ الاستلام: 2020/11/19؛ تاريخ القبول: 2021/02/15

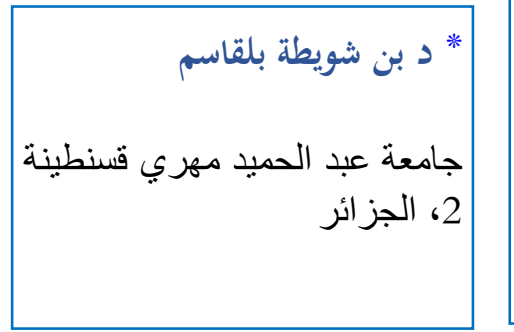

\section{Abstract}

This study aimed to measure the differences in the academic self-concept of students according to the educational levels of the LMD system, and the researcher followed the descriptive approach, where the research sample included (48) students distributed over three levels (second year BA, second year Master And the second year is a Ph.D.), and the researchers used the academic self-concept scale consisting of (30) items, and after applying the tool to the members of the research sample and processing the results by the statistical package (spss) program, the results resulted in:

- The existence of statistically significant differences in the degree of academic selfconcept of graduating students according to the academic level of the LMD system and in favor of doctoral students

Keywords: Academic self-concept; educational system; Students L M D.

\section{Résumé}

Cette étude visait à mesurer les différences dans le concept de soi académique des étudiants en fonction des niveaux d'enseignement du système LMD, et le chercheur a suivi l'approche descriptive, où l'échantillon de recherche comprenait (48) étudiants et étudiantes répartis sur trois niveaux (deuxième année BA, deuxième année Master Et la deuxième année est un doctorat), et les chercheurs ont utilisé l'échelle du concept de soi académique composé de (30) items, et après avoir appliqué l'outil aux membres de l'échantillon de recherche et traité les résultats par le programme de package statistique (SPSS), les résultats ont abouti à:

- L'existence de différences statistiquement significatives dans le degré d'auto-conception académique des diplômés en fonction du niveau académique du système LMD et en faveur des doctorants.

Mots clés: Concept de soi académique; système éducatif; étudiants L M D.

* Corresponding author, e-mail: Belkacem.Benchouita@univ-constantine2.dz 
يعتبر مفهوم الذات أحد الأبعاد المهمة في الشخصية الإنسانية، ويعده البعض فئ

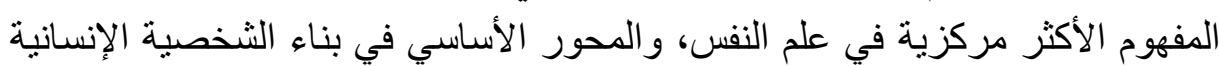

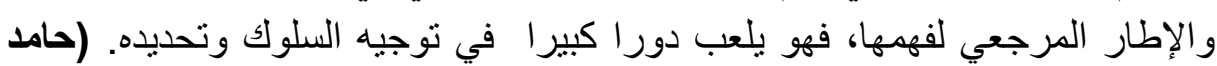

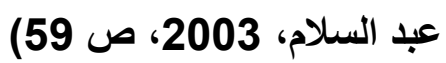

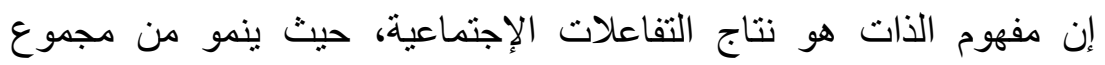

الخبرات والتفاعل مع الآخرين، خلال وضع الفرد في سلسلة من الأدوار الإجتماعية.

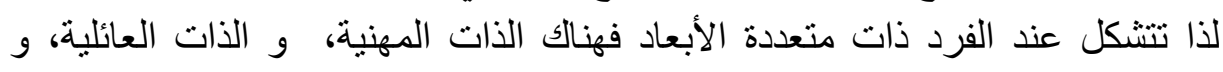

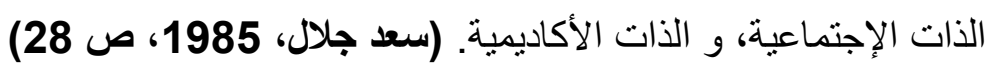

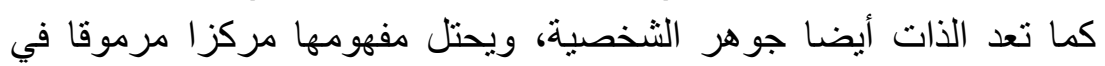

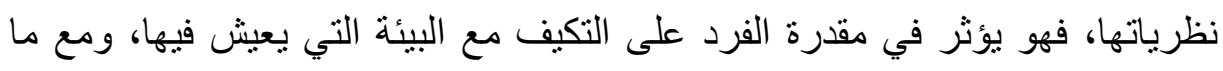
يحيط به من ظروف وخبرات مختلفة، كما يرتبط بالتوافق النفسي الإجتماعي السليم التئي

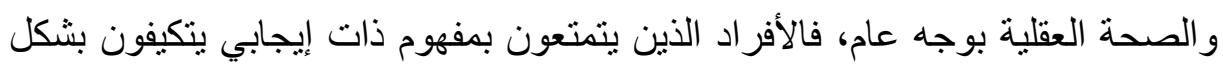

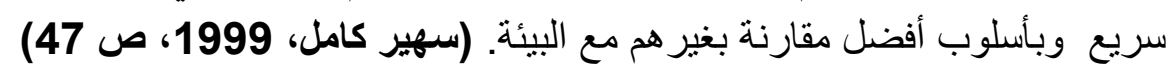

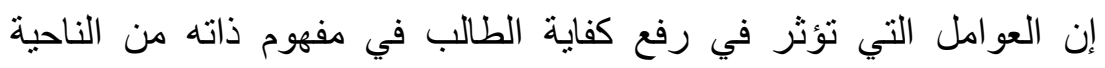

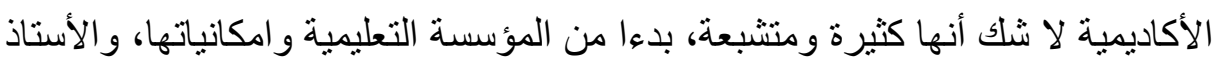

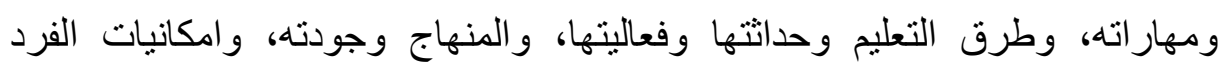

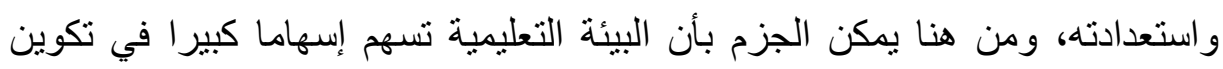

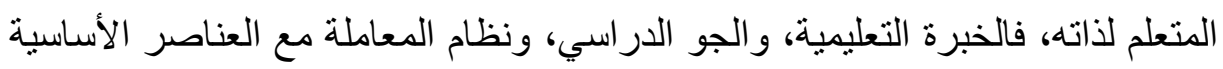

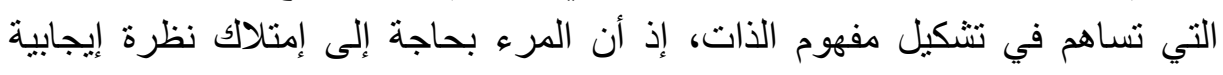

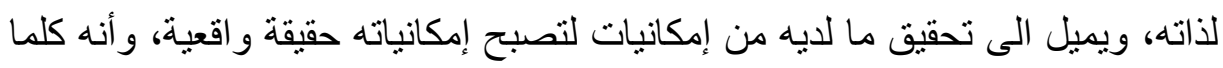
كان المتعلم أكثر إنجاز الكان تقديره لذاته مرتفعا وواقعيا، فالحاجة الى الى تحقيق الذات الذاته

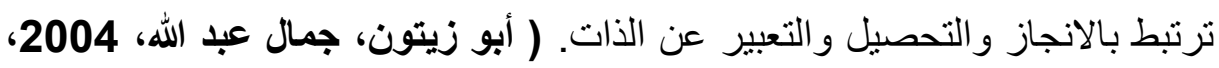

ويمكن القول أن عوامل كثيرة نؤثر في مفهوم الذات، منها ما هو داخلي

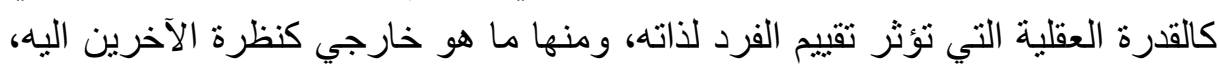
أي أن مفهوم الذات يتأثر بعوامل وراثية و و عوامل بيئية، فالطفل يتأثر في نموه

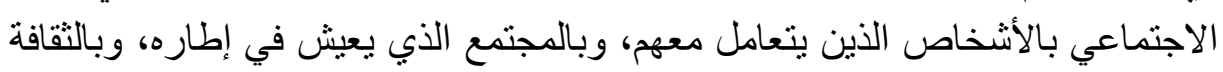

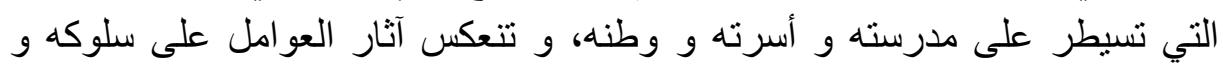

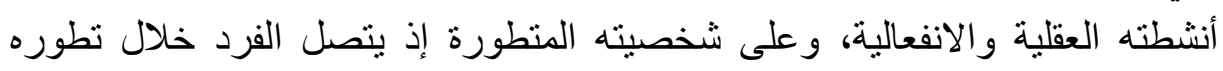

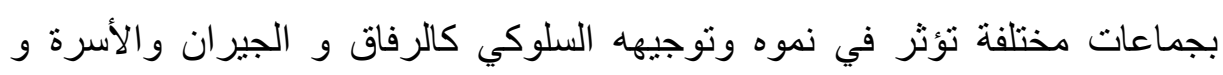

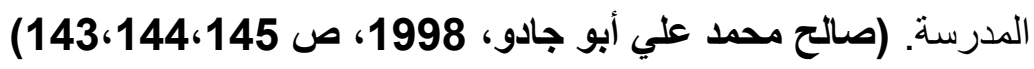

ومن هذا المنطلق جاء موضوع بحثنا الذي يهدف إلى " قياس الفروق في مفهوم

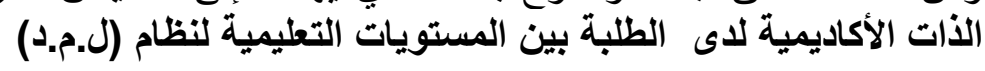




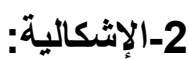

يؤثر مفهوم الفرد عن ذاته على كثثر من جوانب سلوكه، وكما أنه متعلق بشكل مباشر

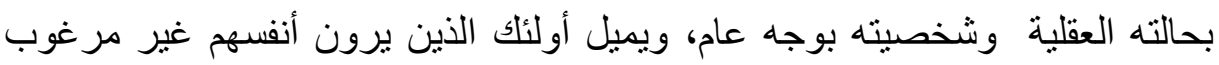

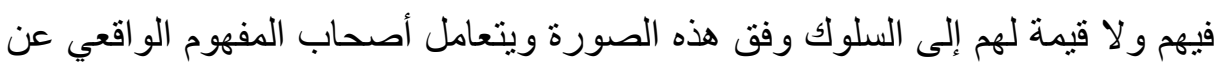

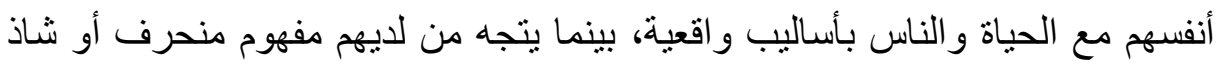

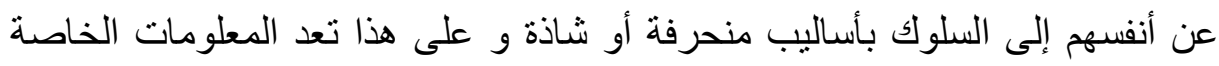

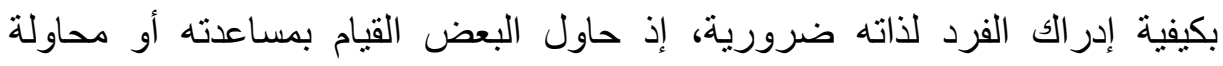

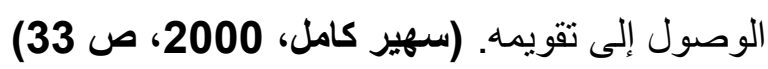

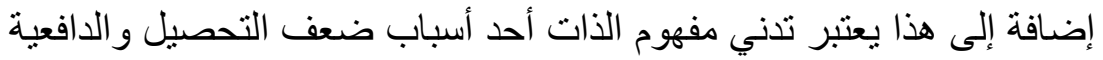
الأكاديمية للاراسة، فالأفراد الذين يشعرون بعدم النفع لا يفكرون بأنفسهم، ويكون

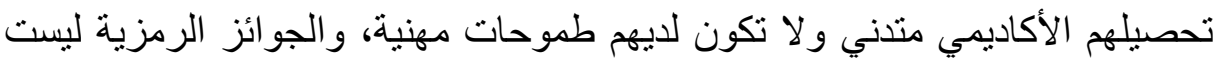

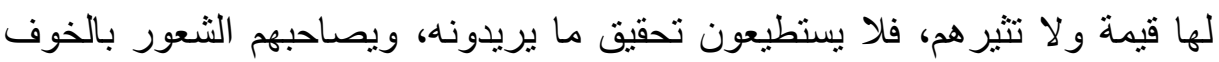

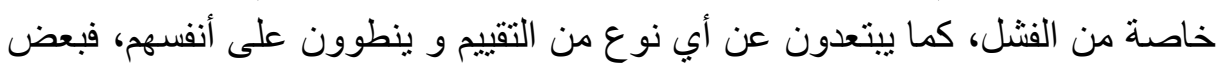

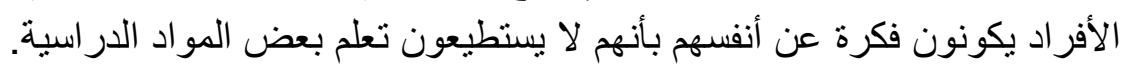

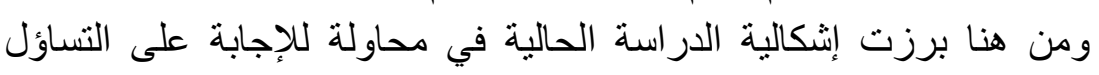
- هل توجد فروق ذات دلالة إحصائية في درجة مفهوم الذات الأكاديمي للطلبة بين

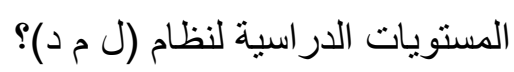
3- الفرضيات:

- هناك فروق ذات دلالة إحصائية في درجة مفهوم الذات الأكاديمي لصالح طلاب

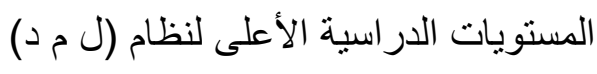

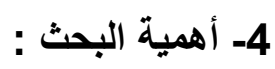
ـ التعرف على الفروق في درجة مفهوم الذات الأكاديمي للطلاب بين المستويات

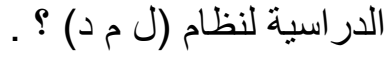
5 - أهداف البحث:

ـ الاستجابة للاتجاهات الحديثة التي تدعو إلى زيادة الاهتمام بموضوع جودة التعليم - زيادة الوعي بأهمية الارتقاء بمفهوم الذات للطلبة من خلال تنمية مهاراتهم وتطوير ها بغية الوصول بأدائهم إلى مستوى عالئه باءلية. 6- المفاهيم و المصطلحات الإجرائية للبحث:

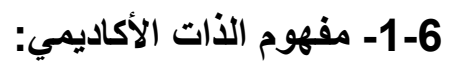
• مفهوم الذات:

عرف كل من "بلكر" و "ستوكنج" pluker \& stocking" مفهوم الذات بأنه

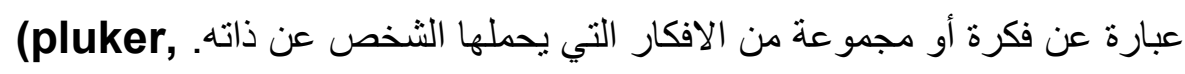


stocking, 2001)

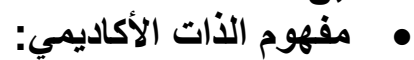

ورد في "أدلر" و"تون" (1990) "Adler \& Towne" أن مفهوم الذات

الأكاديمي يتضمن وصف وتقييم لمدى وعي الفرد بقدراته الأكاديمية. ( Adler \&

( Towne, 1990

- و هو إدر الك الفرد لقدر اته وجهوده في النشاطات الأكاديمية العامة، و النشاطات

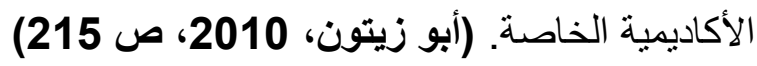

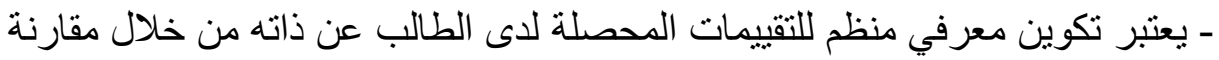

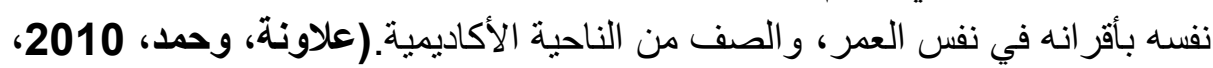

(54 صن (5)

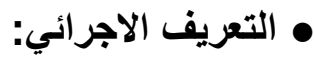

- هي نظرة الفرد لقدر اته الأكاديمية وتتعكس في درجة الاستجابة على مقياس مفهوم

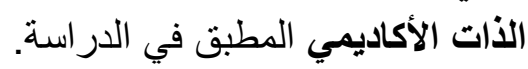

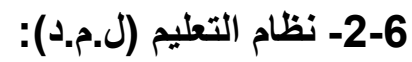

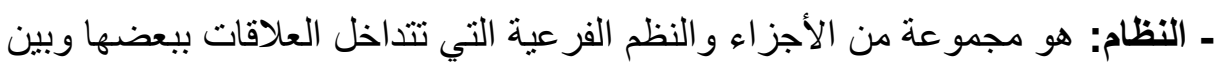

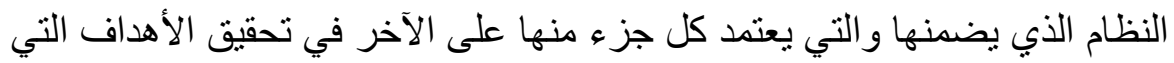

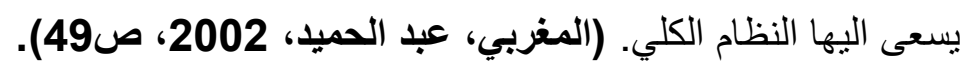

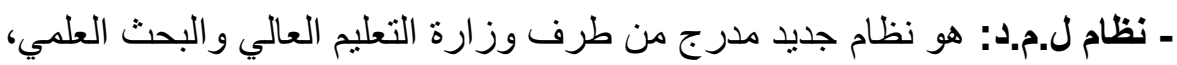

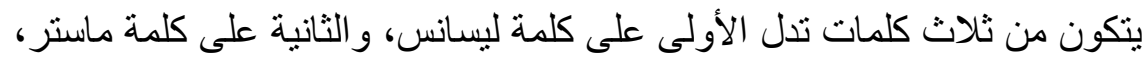
والثالثة على الدكتوراه.(الجريدة الرسمية للجمهورية الجزائرية ولائة، 2014)

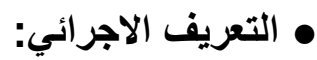

هو نظام للتكوين العالي يرمي الى بناء الدراسة الجامعية على ثلاث مراحل

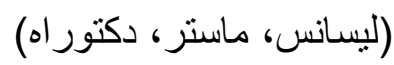

07- الاراسات السابقة والمشابهة التي تطرقت إلى مفهوم الأات الأكاديمي:

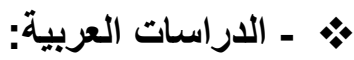

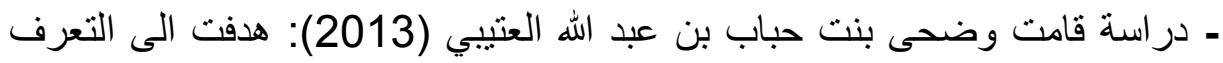

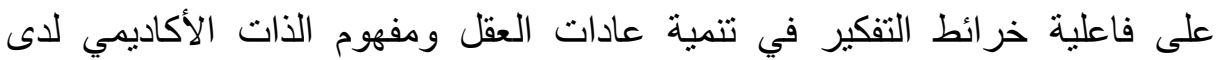

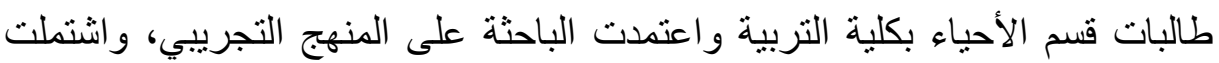

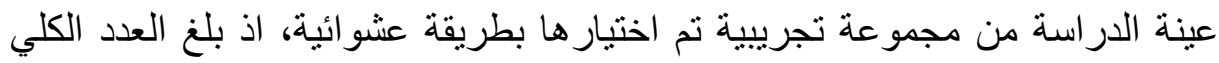

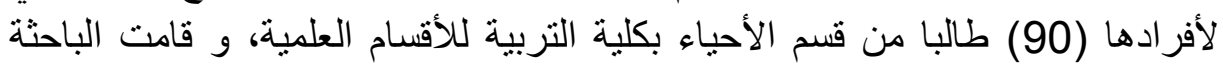

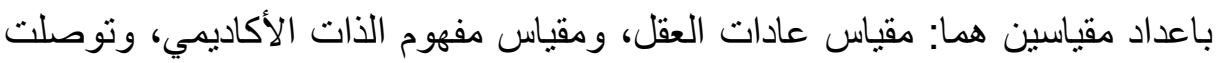

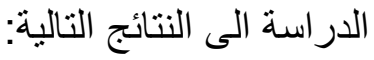

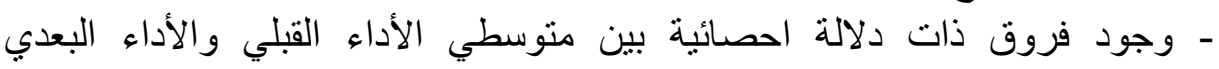
للمجموعة التجرييية في مقياس عادات العقل لصالح أداء المجمو عة التجريبية. 
- وجود فروق ذات دلالة احصائية عند مستوى الدلالة $(0,01)$ بين متوسطي الاداء

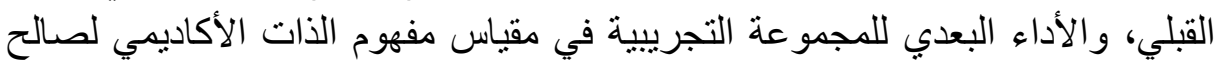
أداء المجمو عة التجريبية. - وجود علاقة ارتباطية موجبة ذات دلالة احصائية عند مستوى الدلالة (0.01) بين درجات طالبات المجموعة التجريبية في مقياس عادات العات العقل، ومقياس مفهوم الذات الأكاديمي في نتائج الأداء البعدي.

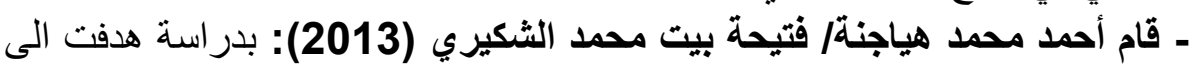

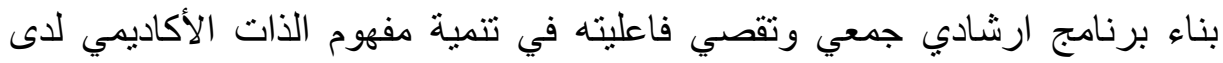

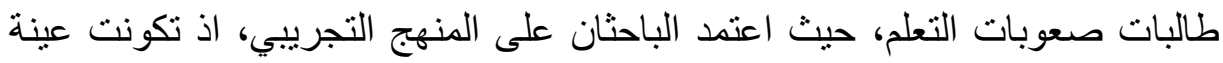

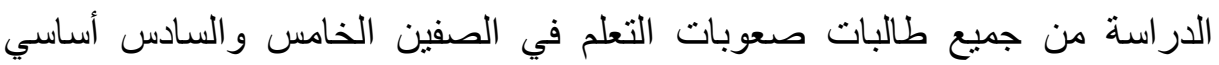

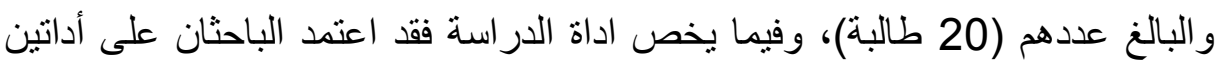

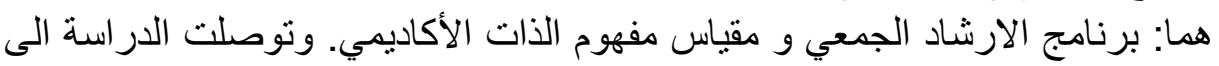

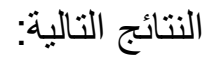
- ـ وجود فروق ذات دلالة احصائية في درجات مفهوم الذات الاكاديمي بين أفراد

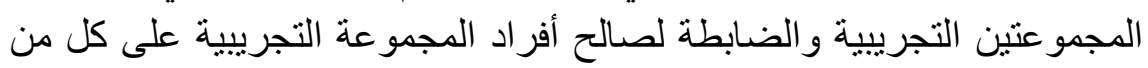

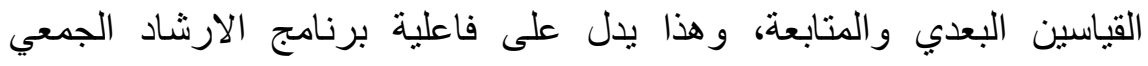

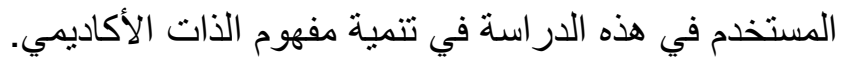

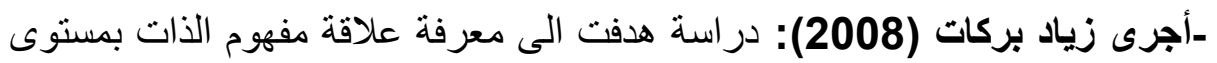

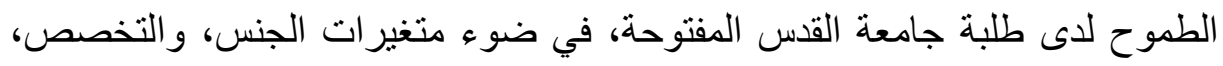

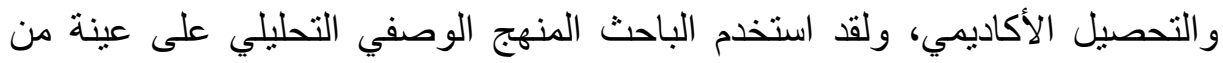

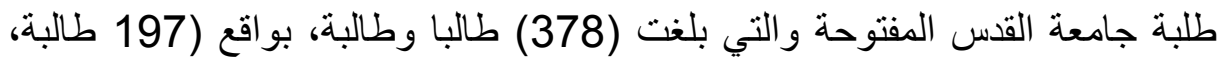

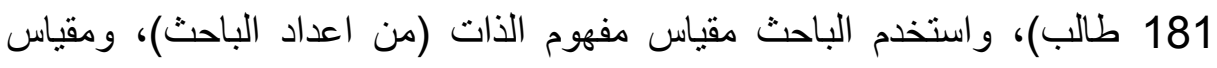

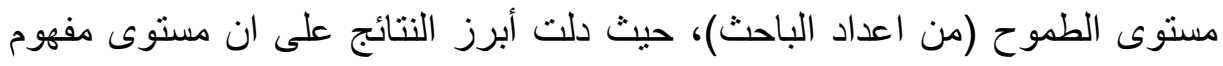

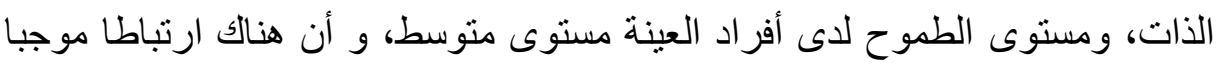

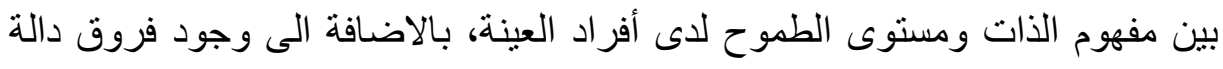

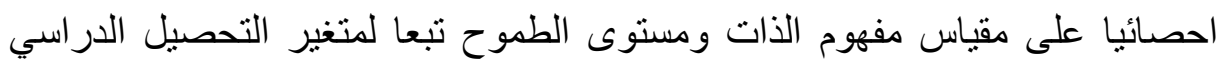

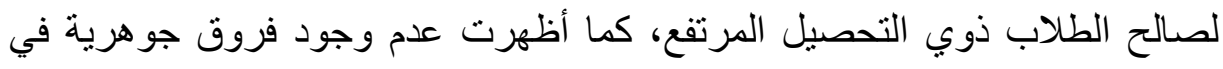
هذه الدرجات تبعا لمتغير الجنس و التخصص.

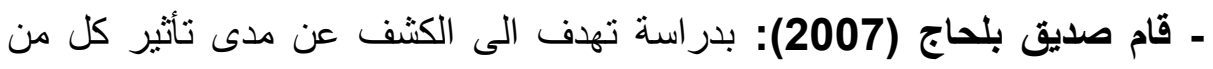

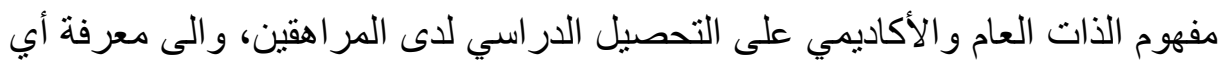

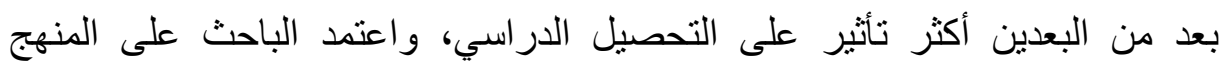

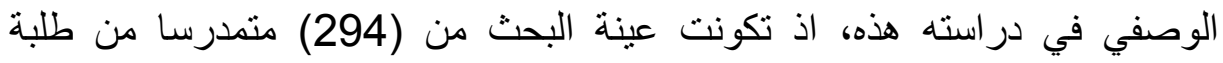

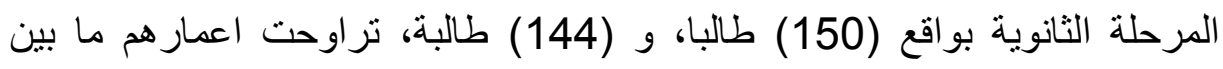

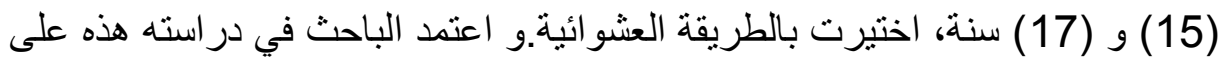

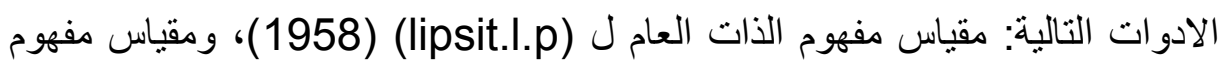

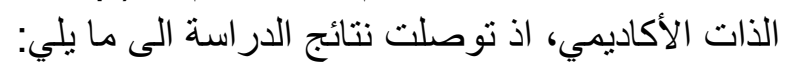
- وجود علاقة ارتباطية ذات دلالة احصائية بين درجات الطات الطاب الطاب في اختيار مفهوم

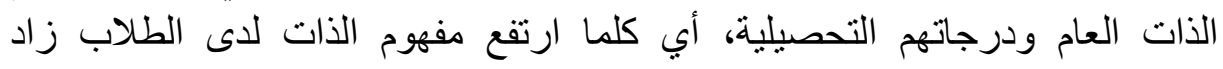
تحصيلهم الدراسي. 
- أن لمفهوم الذات علاقة إرتباطية موجبة بالانجاز الأكاديمي فالتلاميذ ذوو مفهوم

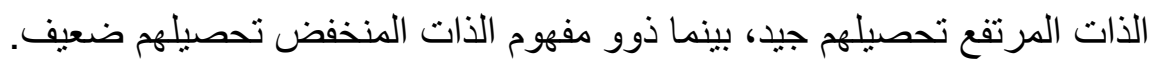

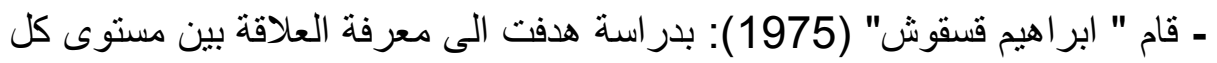

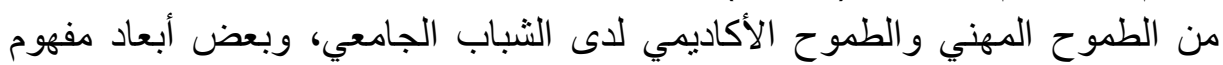

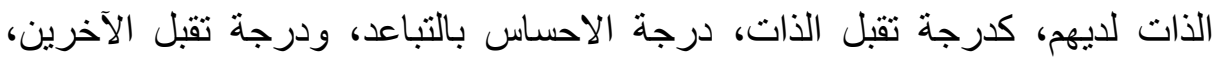

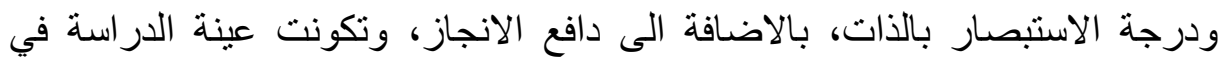

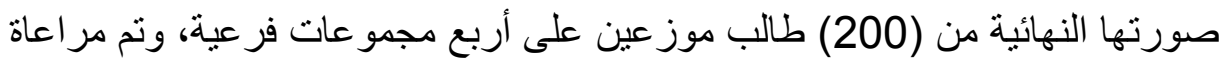

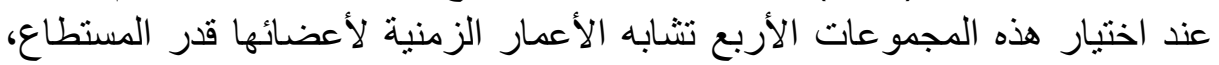

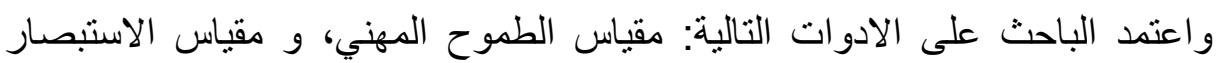

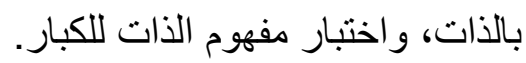

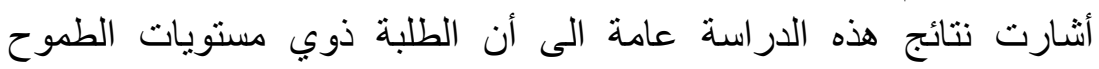

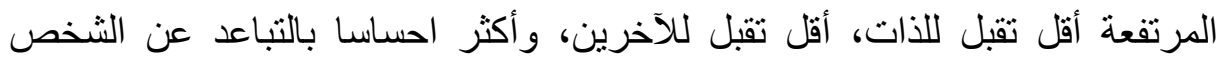

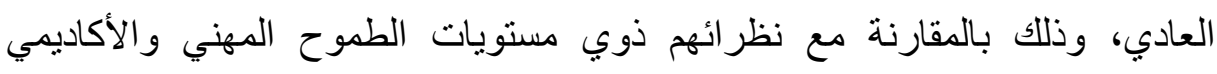
المنخفض.

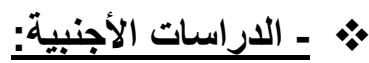

ـ قام "ديان" diane (2003) بإيطاليا: بدراسة هدفت الى تقصي العلاقة بين

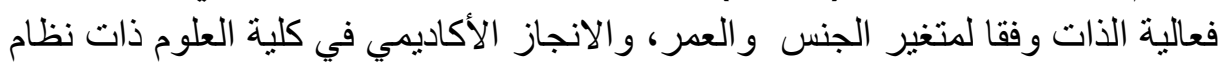

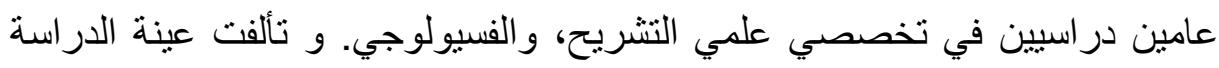

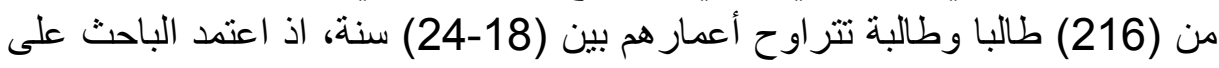

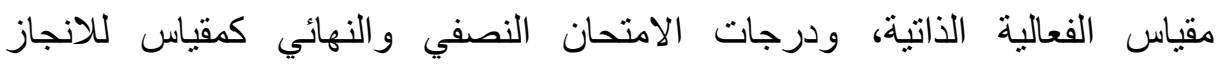
الأكاديمي، فيما خلصت الدر اسة التهة الى النتائج التالية:

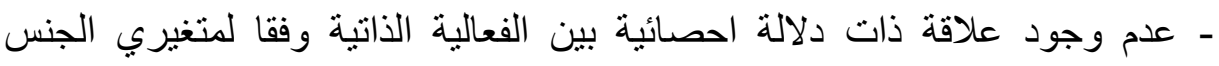

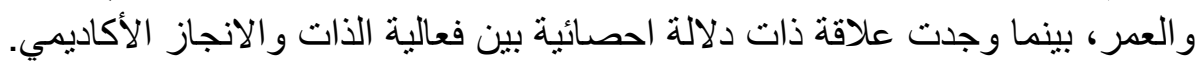

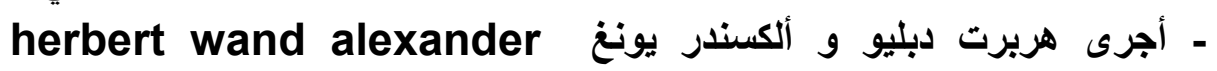
young

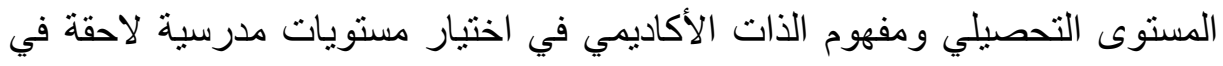
الرياضيات واللغة الانجليزية ( حيث إن نظام التعليم يعتمد على أن الطالب التهي عندما يتم

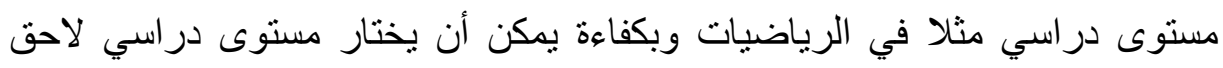

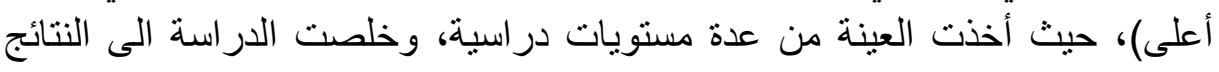
التالية:

وجد أن هناك علاقة ايجابية هامة بين نمو مفهوم الذات الأكاديمي وتدرج

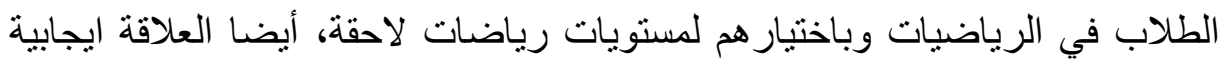

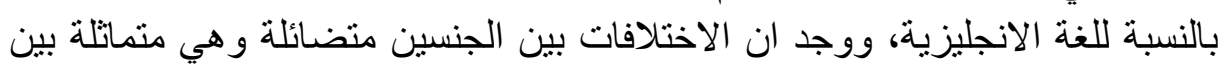
الأكور و الاناث نسبيا.

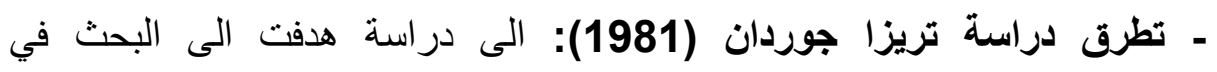

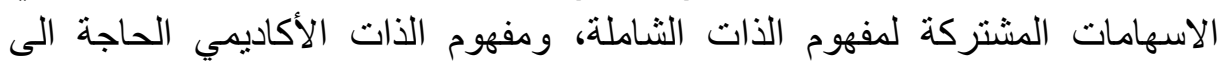
الكفاءة الاكاديمية بخلاف التحصيل الاكاديمي للمر اهقين بالمدن الداخلية، وتألفت عينة 
الدراسة من (368) فردا من طلاب الصف الثامن باحدى المدارس الثانوية الحكومية الداخلية بمدينة نيويورك. وتوصلت الدر ماسة الى الى النتائج التالية: ـ ان مفهوم الذات الثشامل لم يفسر التباين بين الطلاب في التحصيل التبل الأكاديمي المتداخل

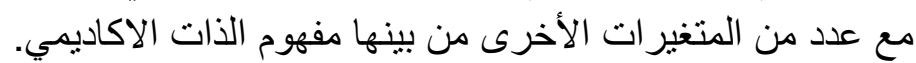

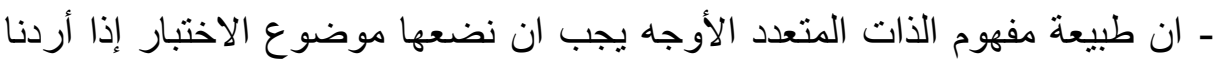
أن نحقق تفسير ات للتباين.

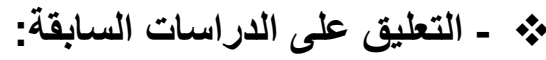

لقد تبين من خلال إستقراء الدراسات السابقة العربية منها والأهاء الأنبية سواءا التي تناولت متغير مفهوم الذات الأكاديمي مايلي:

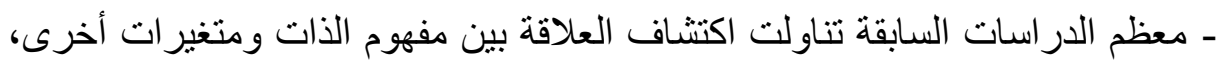
سواءا العربية أو الأجنبية.

ـ أغلب الدراسات التي تناولت مفهوم الذات الأكاديمية استخدمت الأدوات التالية: المقاييس - الاختبارات، بينما الأدوات الأخرى استخدمت بصفة قليلة، وهذا بطبيعة الحال يعود الى طبيعة الموضوعين "الكفايات التعليمية" و "مفهوم الذات الأكاديمي".

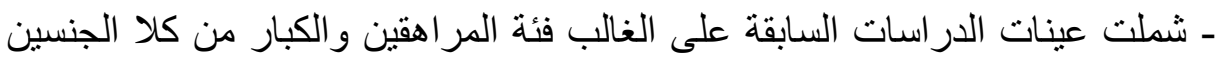

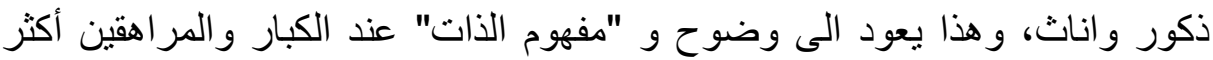
منه عند الأطفال الصغار. ـ أكثر الدراسات السابقة توصلت الى نتائج تؤكد وجود علاقة الهئ بين كل من الكفايات

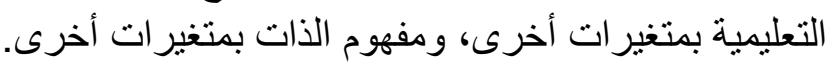

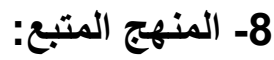
نتطرق في بحثنا هذا إلى موضوع أو ظاهرة من الظواهر التربوية والنفسية

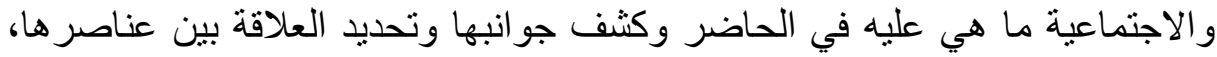

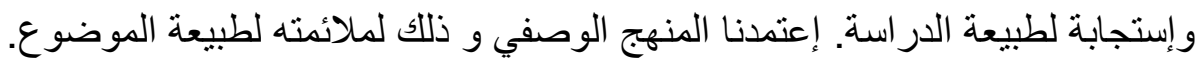

- 1-9 - 1-9 مجتمع البحث:

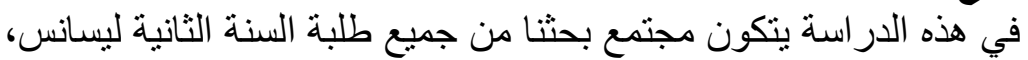

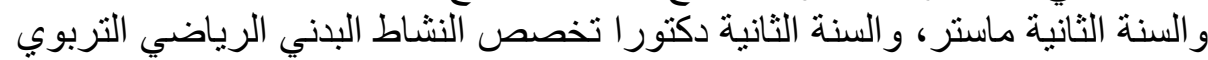

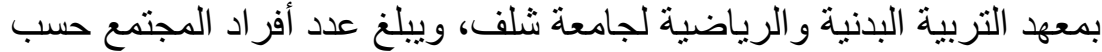

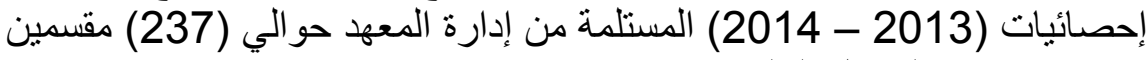
وموضحين في الجدول التالي.

جدول (01): يوضح مجتمع البحث

\begin{tabular}{|c|c|}
\hline عدد الطلبة & المستوى \\
\hline 67 & ليسانس \\
\hline 162 & ماستر \\
\hline 08 & دكتور اه \\
\hline 237 & المجموع \\
\hline
\end{tabular}


2-9 - عينة البحث:

لقد حاول الباحثان أن يحدد عينة لهده الدراسة تكون أكثر تمثيلا للمجتمع

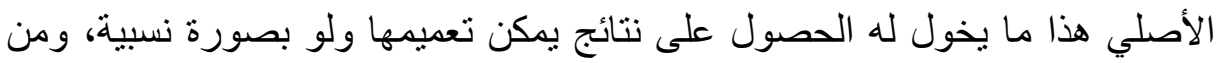

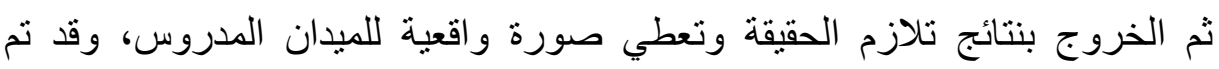

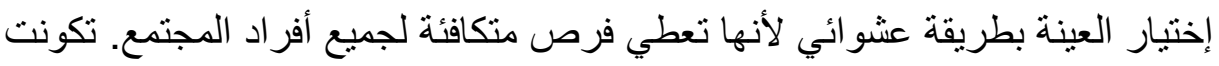

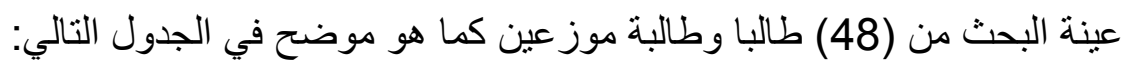

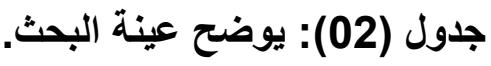

\begin{tabular}{|c|c|}
\hline عدد الطلبة & L \\
\hline 20 & M \\
\hline 20 & D \\
\hline 08 & المستوى \\
\hline 48 & المجوع \\
\hline
\end{tabular}

10- أدوات البحث (مقياس مفهوم الذات الأكادمي): - وصف المقياس:

بعد الإطلاع على عدد من المقاييس المستخدمة في قياس مفهوم الذات في

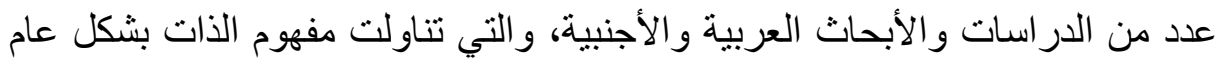

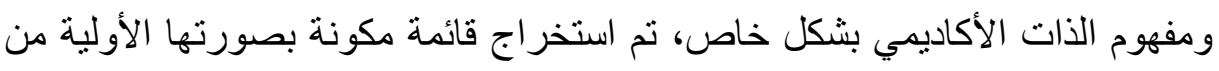

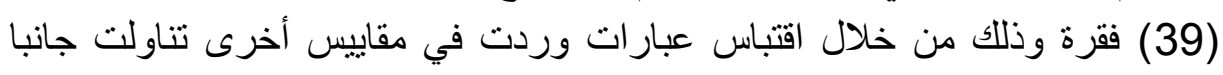

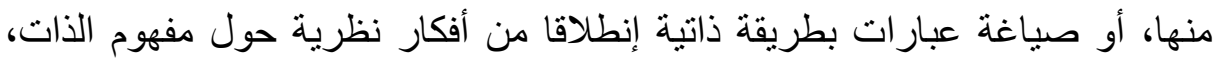

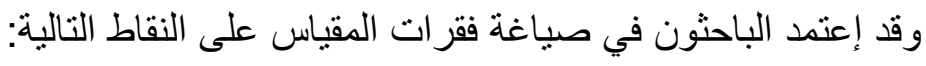
ـ أن لا تكون الفقرة طويلة بمفرداتها بحيث تؤدي إلى إنى الملل في الإجابة.

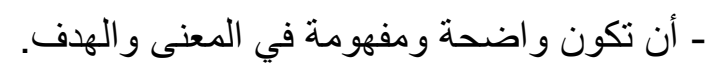

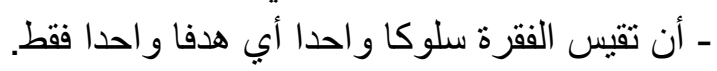
ـ ـ أن تتضمن فقر ات المقياس مجالاته. - مفتاح تصحيح المقياس:

سلم تصحيح من (01) إلى (05) درجات بالنسبة للبنود الموجبة، والعئه العكس

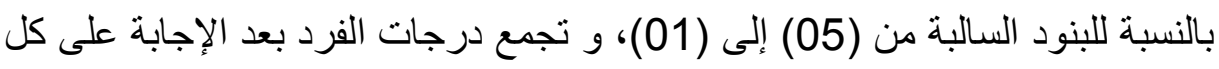

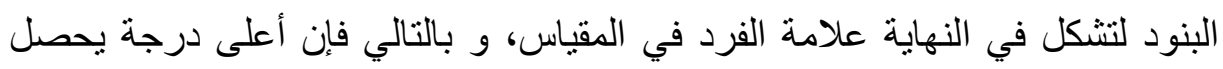

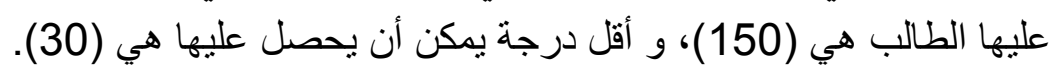

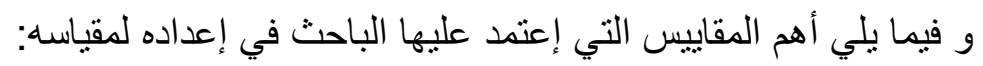
1- إختبار تقدير الذات من إعداد الباحثين: "عبد العزيز الدريني" و "عبد الوهاب

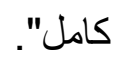
2- مقياس مفهوم الذات الأكاديمي لذوي صعوبات التعلم من إعداد الباحث: "هيثم 
راشد أبو زيد".

3- إختبار تقدير الذات بصيغته العربية ل: "روزنبرغ غون".

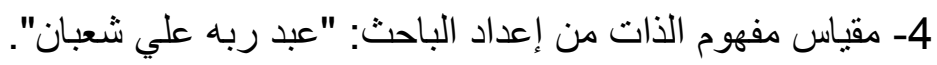

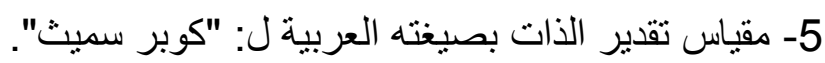

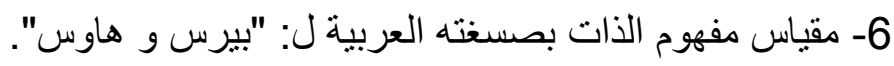

7- مقياس تقدير الذات ل: "بروس أرهير".

ـ الخصائص السيكومترية للمقياس:

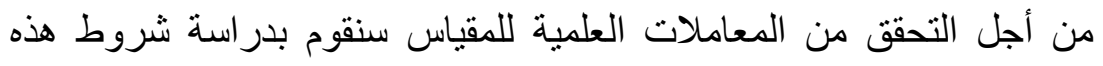

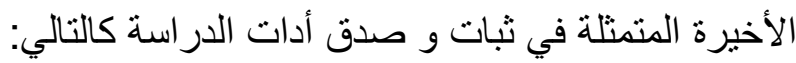

ل

لقد تم حساب معامل ثبات المقياس في الدراسة الحالية بالطريقة التالية:

- طريقة إعادة الإختبار: (test- retest):

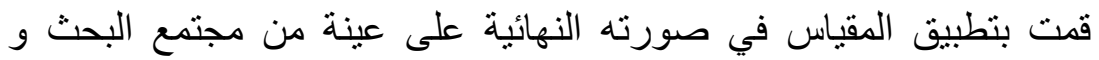

خارج عينة الدراسة الأساسية، و نتكون من (20) طالبا وطالبة بمعهد التربية البدنية و الرياضية بجامعة الثلف، وبعد مرور أسبو عين أي (15) يوما من تطبية الإسيق الإختبار

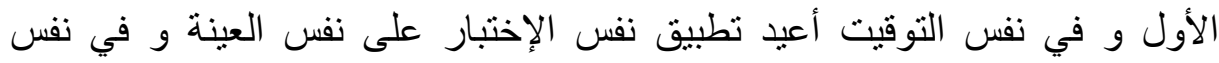

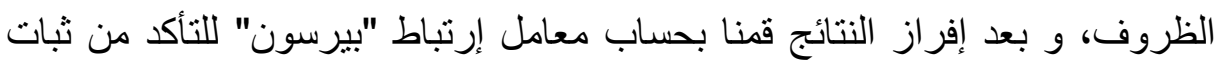
الإختبار ، و الجدول التالي يوضح لنداز النا النتائج كالتالي:

الجدول (03): يوضح معاملات الإرتباط بين التطبيق الأول والثاني

لمقياس مفهوم الذات الأكاديمي لارجة الكلية للمقياس.

\begin{tabular}{|c|c|c|}
\hline مستوى & معامل الإرتباط بين التطبيق الأول و & الألات الأكاديمي مفهوم \\
\hline 0,05 & 0,822 & للارجة الكلية \\
\hline
\end{tabular}

يتضح من الجدول أعلاه أن معامل الإرتباط لبيرسون بلغ (0,822) ، وهي

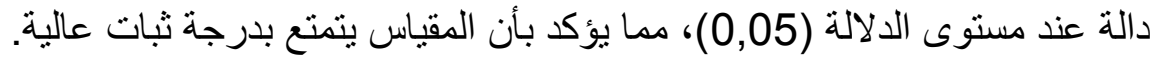
$\checkmark$ - صدق المقياس: إعتمد الباحث في حساب صدق المقان المقياس على ما يلي:

\section{الصدق الظاهري (صدق المحكمين):}

بعد إجر اءات بناء المقياس وقبل محاولة تطبيقه على عينة البحث فقد عرض المبل

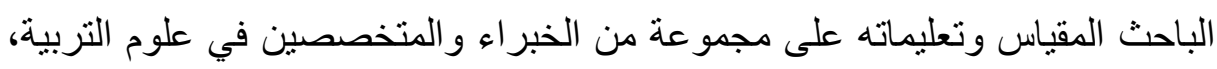

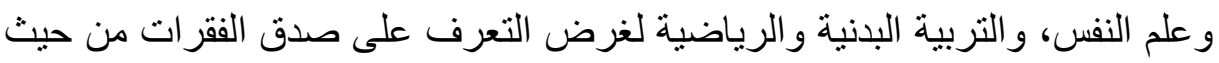

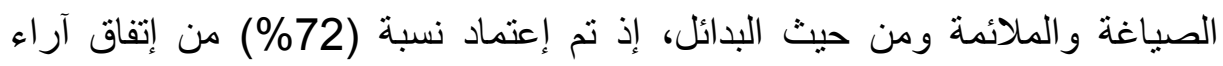

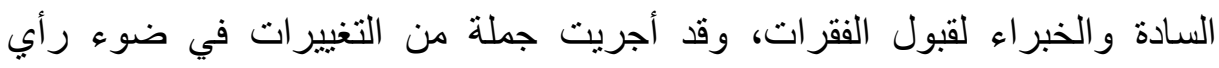

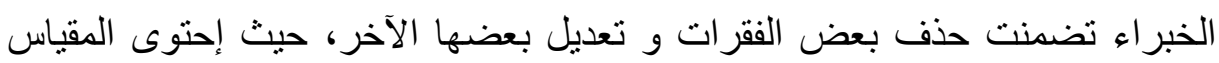

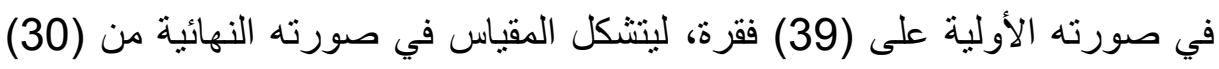




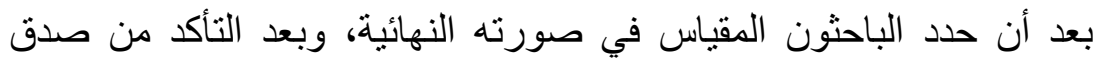

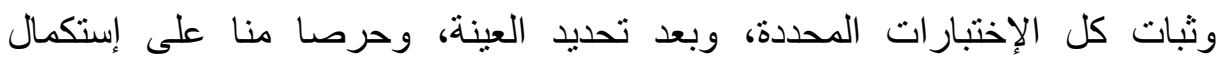
الإجراءات الضرورية حتى تكون إجابة المفحوص (الطالب) مطابقة تماما لرأيه أليه

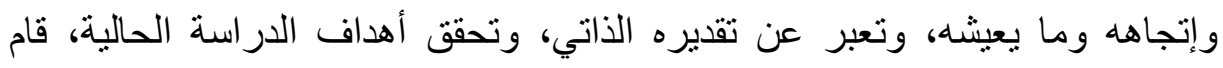

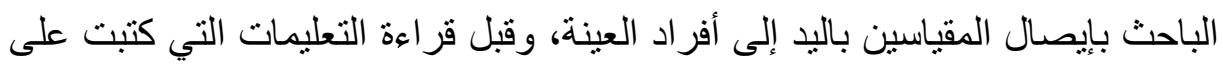

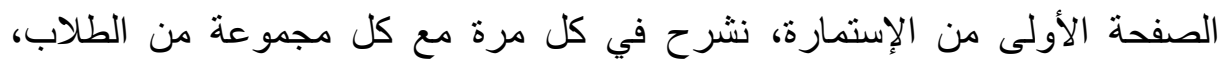

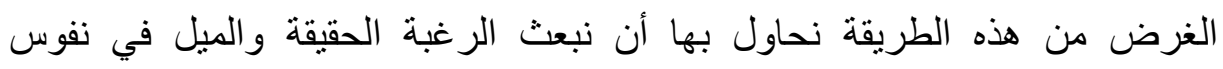

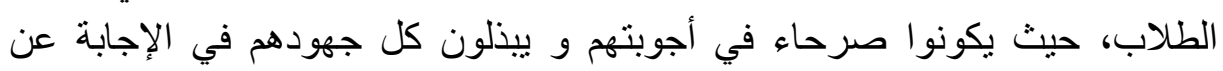

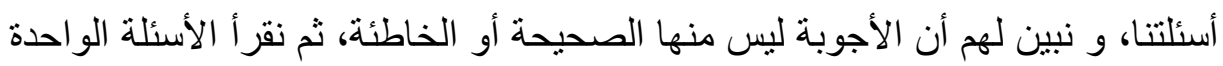

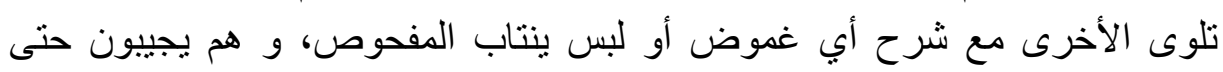

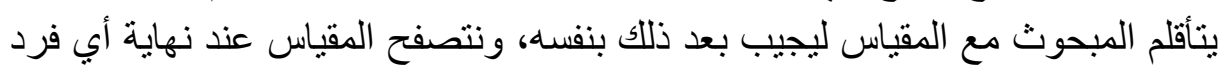

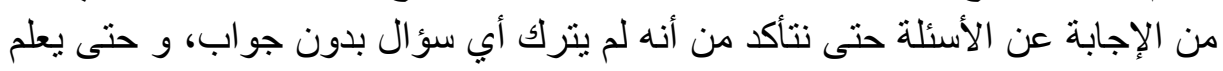
الجميع مرة أخرى أن كل سؤال مهم الإجابة الإسية عنهـ. 12- الأساليب الإحصائية المتبعة: الخئ:

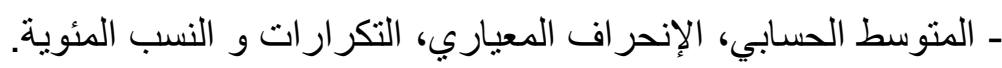

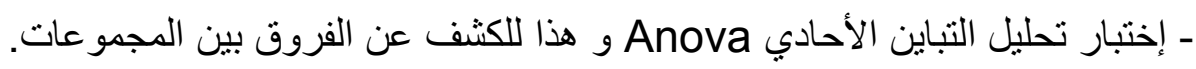

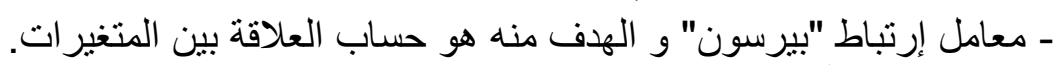
ل ملاحظة: تمت المعالجة الإحصائية بواسطة إستخدام الحزمة الإحصائية

"Spss. V 17"

\section{3- عرض ومناقثة نتائج البحث:}

- هناك فروق ذات دلالة إحصائية في درجة مفهوم الذات الأكاديمي للطلاب بين

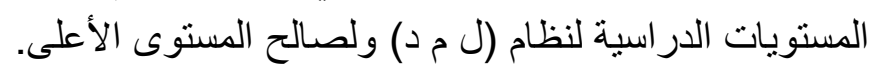
- جدول (04): يوضح تحليل التباين بين درجات مفهوم الذات الأكاديمي للطلاب بين

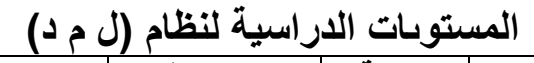

\begin{tabular}{|c|c|c|c|c|c|c|c|c|}
\hline الدلالة & الدلالة & SIG & $F$ & مجموعط & الحرية & المربعوات & التباين & المتغير \\
\hline \multirow[t]{2}{*}{ إحصائيا } & \multirow[t]{2}{*}{0,05} & \multirow[t]{2}{*}{0,000} & \multirow[t]{2}{*}{32,18} & 3567,80 & 2 & 7135,61 & المجموعات & \multirow[t]{2}{*}{ الأكاداتيمية } \\
\hline & & & & 108,71 & 45 & 4892,30 & المجموعات & \\
\hline
\end{tabular}




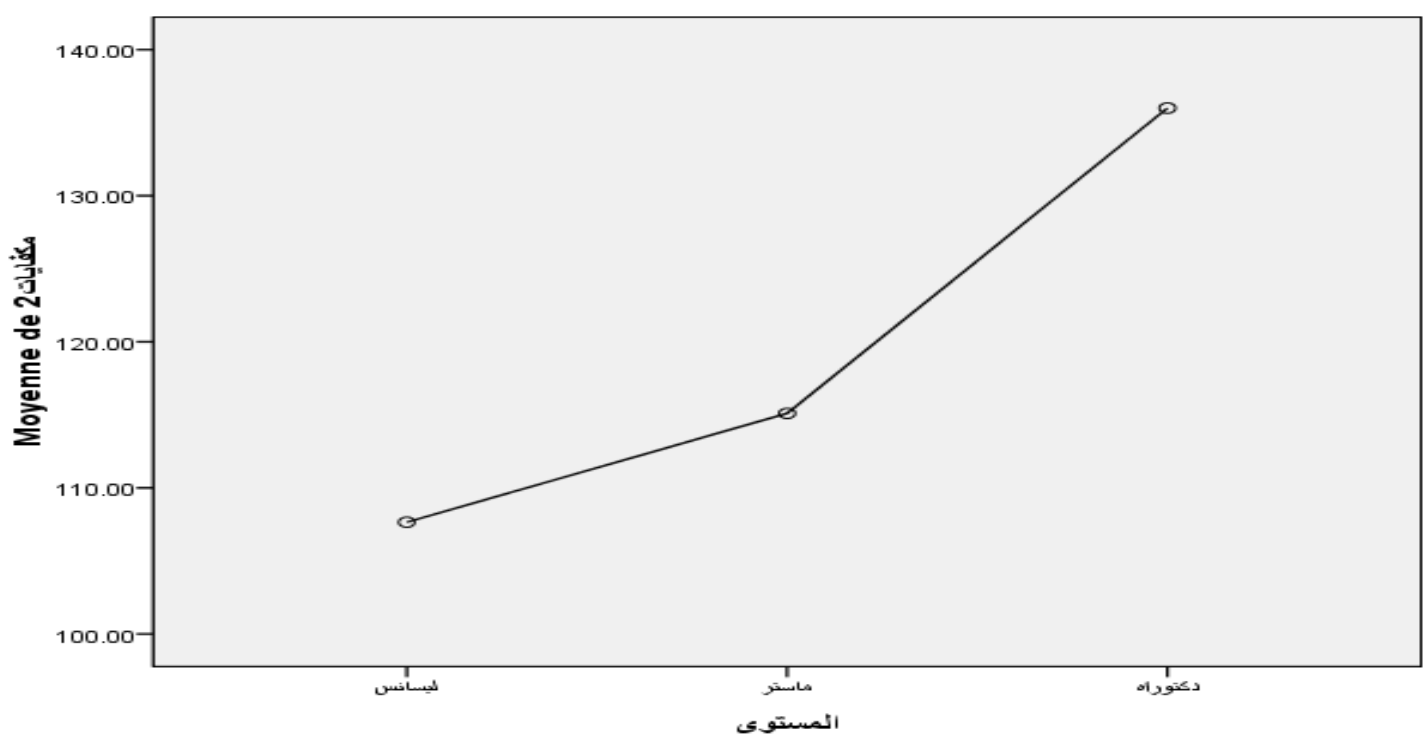

ـ شكل (01): يوضح تحليل التباين بين درجات مفهوم الأت الأكاديمي للطلبة بين

\section{المستوسات الدراسية لنظام (ل م د)}

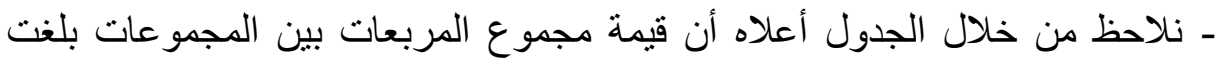
(7135,61)، ومتوسط مجموع المربعات أو (التباين) فبلغت قيمته (3567,80)

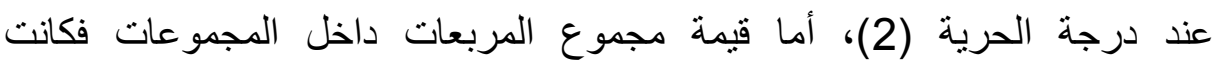

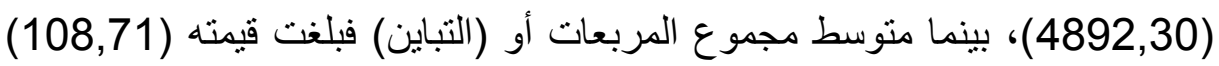
عند درجة الحرية (45)، وبلغت قيمة F) F) (32,18)، وبما أن قيمته (sig) بلغت فئت

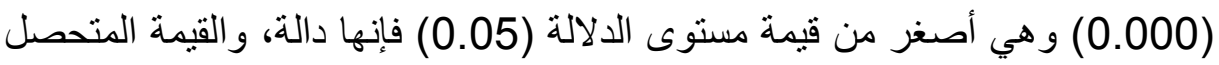

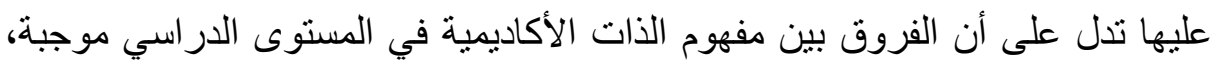
و هذا يعني أن هنالك فروق ذات دلالة إحصائية في درجة مفهوم الذات الأكاديمية

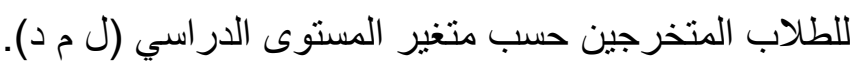
جدول (05) يوضح إتجاه دلالة الفروق حسب متغير المستوى الدراسي لنظام

\begin{tabular}{|c|c|c|c|c|c|}
\hline \multicolumn{6}{|c|}{ (J.J.د) } \\
\hline الدلالة & مستوي & الخعياري & الإختّلاف في & المستوى & المتغير \\
\hline \multirow{2}{*}{ دالة } & 0.07 & 2.24 & -7.45 & $\mathrm{M}$ & \multirow{6}{*}{ الأكاداتِ } \\
\hline & 0,00 & 2.97 & -28.35 & $\mathrm{D}$ & \\
\hline \multirow{2}{*}{ دالة } & 0.07 & 2.24 & 7.45 & L & \\
\hline & 0,00 & 2.97 & -20.90 & $\mathrm{D}$ & \\
\hline \multirow{2}{*}{ دالة } & 0,00 & 2.97 & 20.90 & $\mathrm{M}$ & \\
\hline & 0,00 & 2.97 & 28.35 & L & \\
\hline
\end{tabular}


نلاحظ من خلال الجدول أن إتجاه دلالة الفروق بين قيمة مستوى الدلالة عند

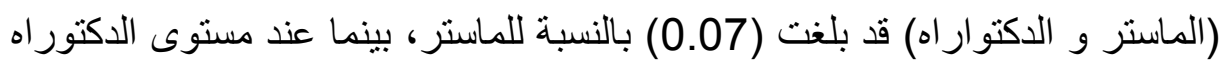

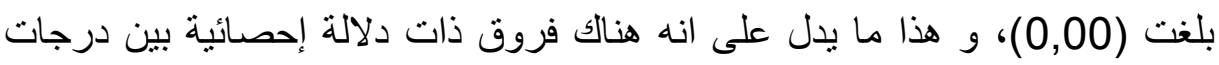

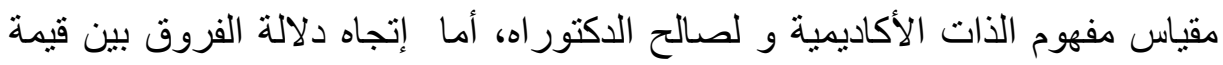

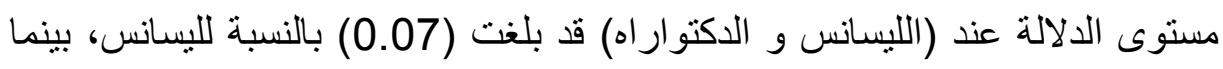

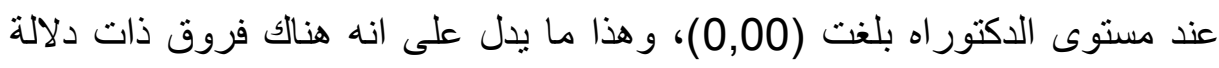

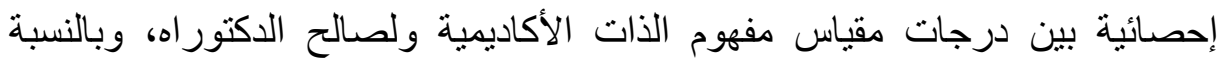

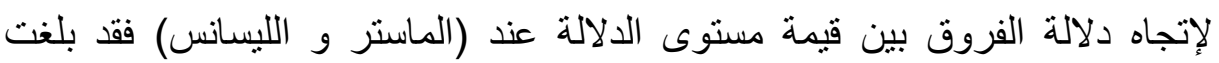

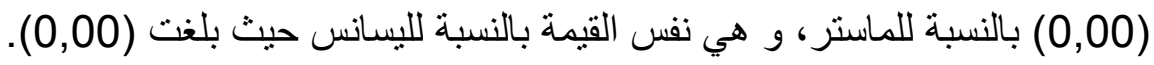

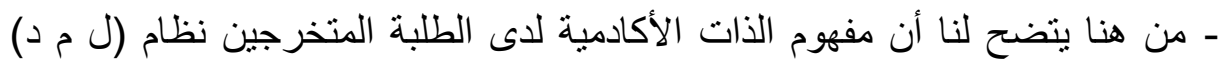

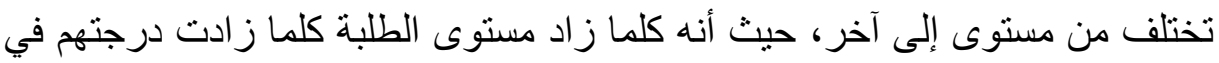

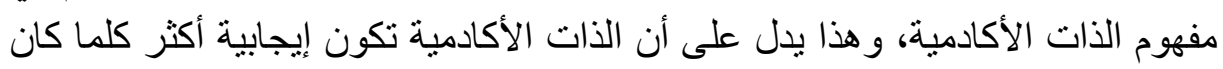

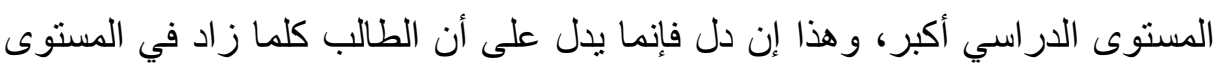

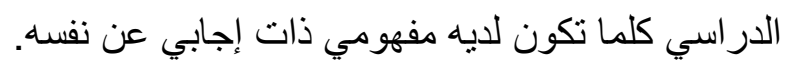

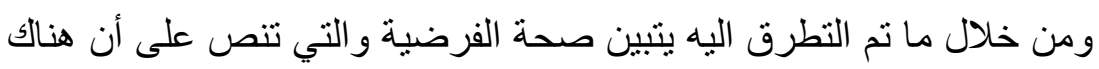

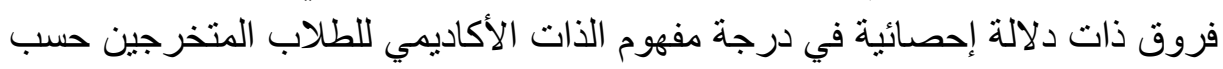
متغير المستوى الدراسي (ل مد د).

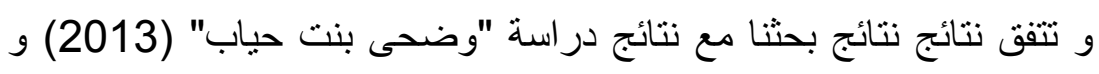
التي أسفرت على وجود فروق ذات دلالة إحصائية في مقياس مفهوم الذات الاكاديمية لئية

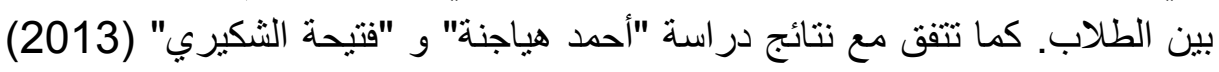

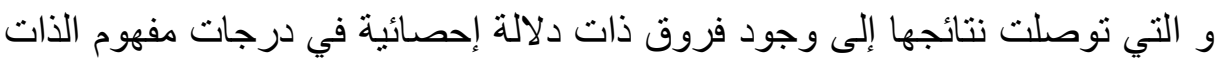

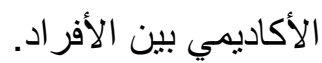

و يمكن تفسير ذلك في إطار ما يراه "مارشيا" (1970) من أن الفرد عندما

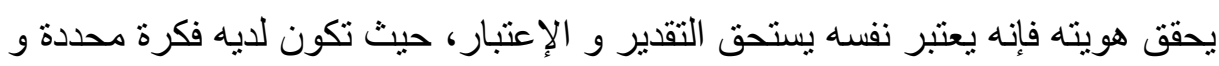

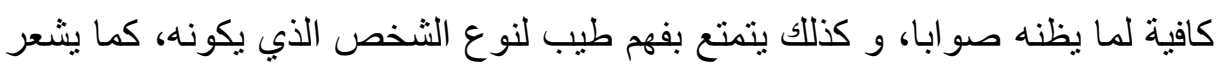

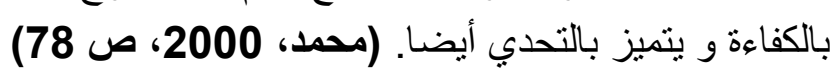
و يؤكد "هاماثك" (1978) أن الأشخاص الذين لديهم مفهوم ذات أكادئ أناديمي مرتفع يعتقدون أنهم ذو قيمة و أهمية، و أنهم جديرين بالإحترام و الإنقائ التهاير، كما أنهم

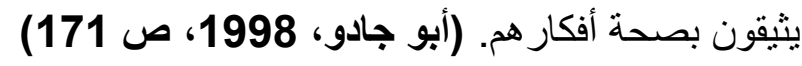
و يضيف "كفافي" (1997) أن مفهوم الذات الأكاديمي الإيجابي يعني وجود الندا

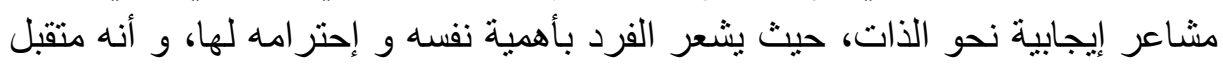

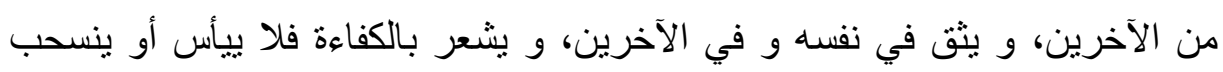

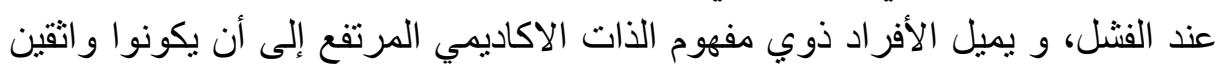

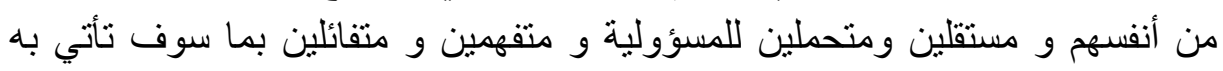

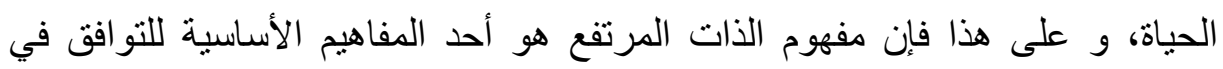

مختلف مجالات الحياة. (كفافي، 1997، صفئ صم 503) 
ـ نصت فرضية البحث على وجود فروق ذات دلالة إحصائية في درجة مفهوم الذات

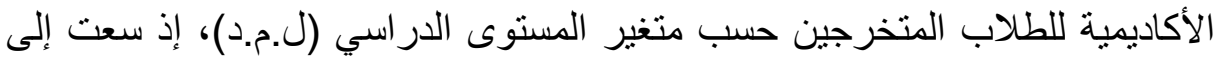

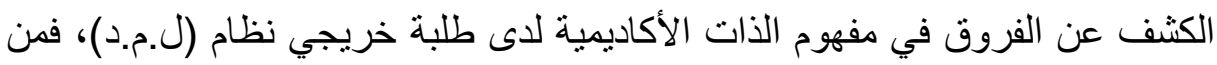

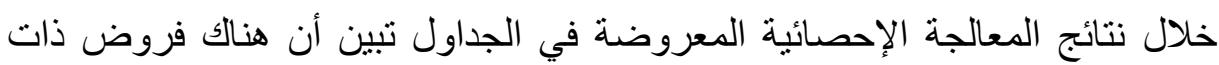

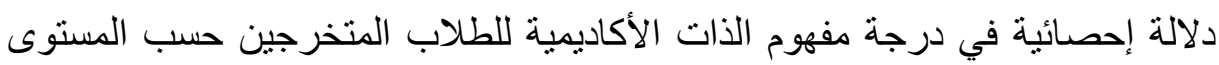

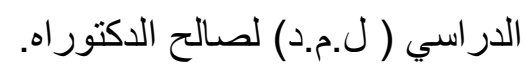

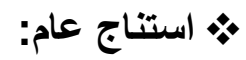

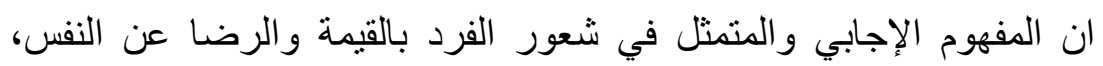

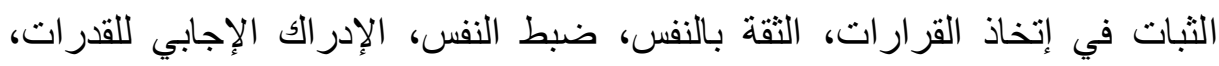

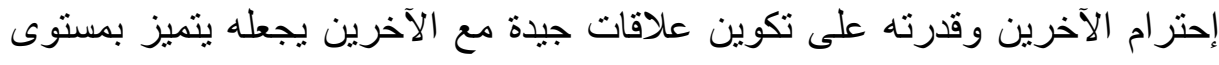

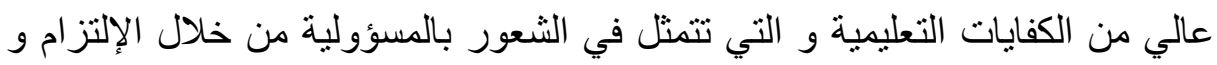

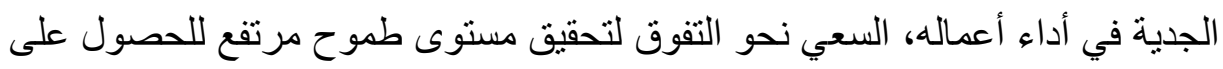

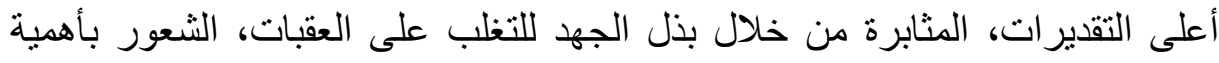

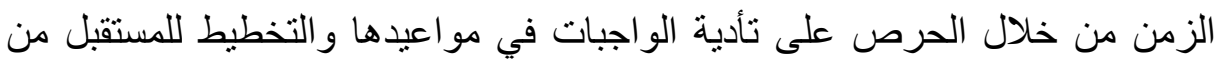

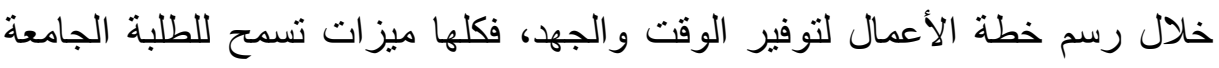

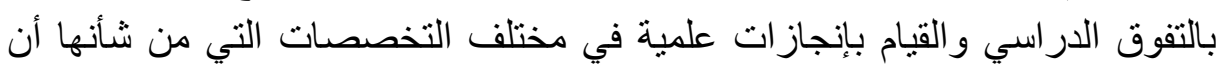

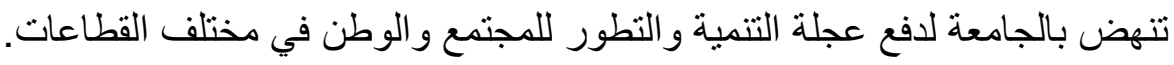

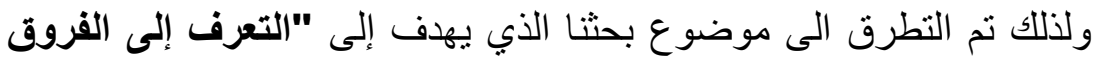

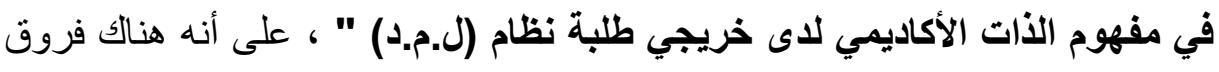

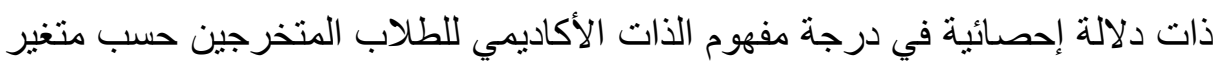
المستوى الدر اسي (ل م د).

\section{• الإقتراحات والبحوث المستقبلية:}

في ضوء ما أسفر عنه هذا البحث من نتائج يوصي الباحثون مايلي:

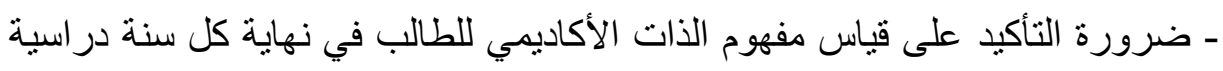

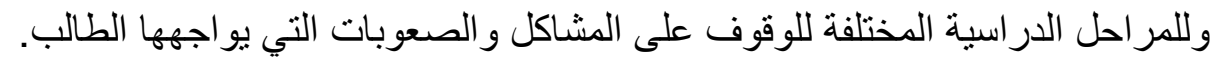

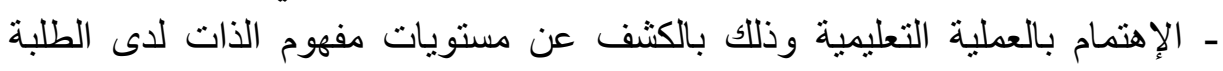

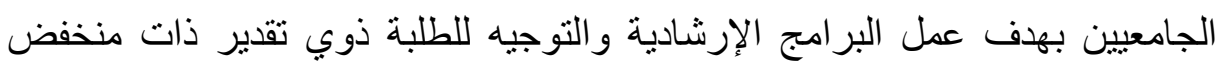
لمساعدتهم على تكوين صورة إيجابية عن أنفسهم وتقبلهم لها ومن ثم تقدير هم لها. 
1- أبو جادو صالح (1998): سيكولوجية التنشئة الإجنماعية، دار المسير، عمان. 2- أبو زيتون جمال عبد الله (2004): أثر برنامج تدريبي في تنمية المهارات

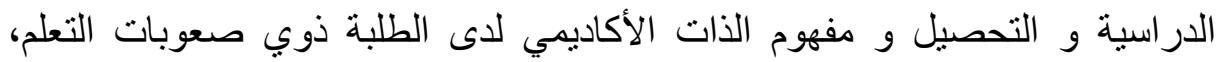
رسالة دكتور اه غير منشورة، الجامعة الأردنية، عمان الأردن.

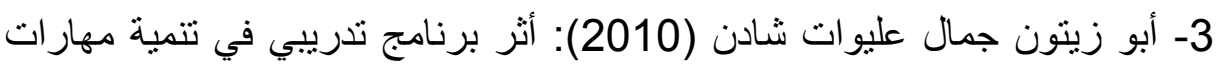

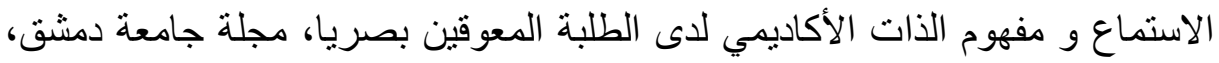
المجلد (62)، العدد الرابع.

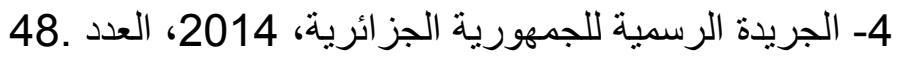

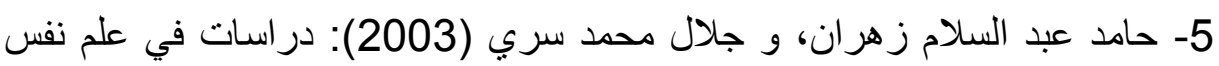

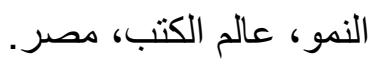

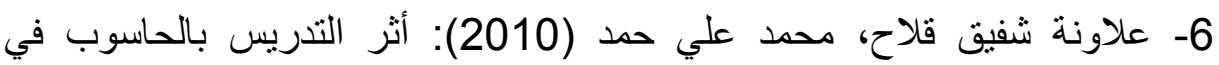
التحصيل و مفهوم الذات الأكاديمي لدى طلبة الصف الثالث أساسي، مجلة العلوم التربوية و النفسية، البحرين، المجلد (11)، العدد الأول. 7- سعد جلال (1985): الطفولة والمراهقة، دار الفكر العربي، القاهرة.

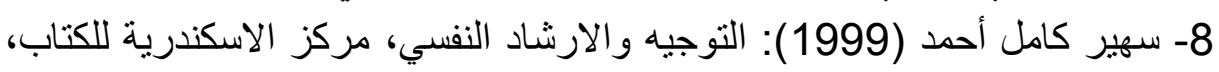

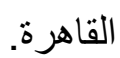
9- سهير كامل أحمد (2000): سيكولوجية النمو، مركز الاسكندرية للكتاب، مصر. • المراجع الأجنبية:

10- adler.r.b \& towne.n (1990). Looking out/ looking in. fortworth: holt. rinehart and winstom. Inc.

11 - Mon bourquette. G (2002) : de léstime de soia léstime de soi de ta psychologie a la spiritulaite, noualis bayard.

12- pluker, j. a. stocking. Vb (2001) looking outside and inside: self- concept development of gifted adolescents. Gifted child ouarterly. 